\title{
Solar Selective Coatings for High Temperature Applications
}

\author{
Donald A. Jaworske ${ }^{1}$ and Dean A. Shumway ${ }^{2}$ \\ 'NASA Glenn Research Center, 21000 Brookpark Rd., Cleveland, OH 44135 \\ ${ }^{2}$ Brigham Young University - Idaho, Rexburg, ID 83460 \\ 216-433-2312; Donald.A.Jaworske@grc.nasa.gov
}

\begin{abstract}
Solar selective coatings are envisioned for use on minisatellites, for applications where solar energy is to be used to power heat engines or to provide thermal energy for remote regions in the interior of the spacecraft. These coatings are designed to have the combined properties of high solar absorptance and low infrared emittance. The coatings must be durable at elevated temperatures. For thermal bus applications, the temperature during operation is likely to be near $100^{\circ} \mathrm{C}$. For heat engine applications, the temperature is expected to be much greater. The objective of this work was to screen candidate solar selective coatings for their high temperature durability. Candidate solar selective coatings were composed of molecular mixtures of metal and dielectric, including: nickel and aluminum oxide, titanium and aluminum oxide, and platinum and aluminum oxide. To identify high temperature durability, the solar absorptance and infrared emittance of the candidate coatings were evaluated initially, and after heating to temperatures in the range of $400^{\circ} \mathrm{C}$ to $700^{\circ} \mathrm{C}$. The titanium and aluminum oxide molecular mixture was found to be the most durable.
\end{abstract}

\section{INTRODUCTION}

Solar selective coatings are envisioned for use on minisatellites, for applications where solar energy is to be used to power heat engines or to provide thermal energy for remote regions in the interior of the spacecraft. The coatings are designed to exhibit reflectance values that yield the combined properties of high solar absorptance and low infrared emittance. A sharp transition in the optical properties must occur at a wavelength determined by the desired surface temperature. These unique optical properties must remain durable at designed operating temperatures. For thermal bus applications, the temperature during operation is likely to be near $100^{\circ} \mathrm{C}$. For heat engine applications, temperature during operation is likely to be much greater. Low temperature differential Stirling engines are envisioned to have a temperature input in the vicinity of $450^{\circ} \mathrm{C}$ with heat engine efficiency improving with increasing input temperature.

Much of the theory for using solar thermal energy conversion for space power has been worked out in detail (Hahn, 1978). The solar flux outside of the Earth's atmosphere impinges on a concentrator and the concentrated flux is directed onto a heat absorber surface coated with a solar selective coating. A concentration ratio on the order of 100 would be ideal for heat engine applications. Figure 1 shows an artist's concept of such a heat engine, with the annular heat absorbing surface near the focus of the concentrator coated with a dark solar selective coating. In this concept, the heat absorbing surface powers a 33 watt Stirling convertor. Other concepts utilizing dome-like Fresnel lenses coupled to Micro Electro Mechanical System (MEMS) heat engines are also being envisioned. Such MEMS devices may offer the advantages of mass production and could be placed in arrays. Negligible change in performance from beginning-of-life to end-of-life may also make these MEMS heat engines attractive.

Early solar selective coatings designed for use in terrestrial systems were applied to flat plate collectors (Granqvist, 1991). More recent work showed that solar selective coatings could be applied to glass tubes at the focus of trough style collectors (Zhang, 1999). Sputter deposition was used to produce the molecular mixtures of metal and dielectric on the surface of the glass tubes. A tungsten and aluminum nitride combination was found to be a successful candidate. Additional work on solar selective coatings for space power applications utilized ion beam sputter deposition, where the molecular mixtures of metal and dielectric were made with a customized 


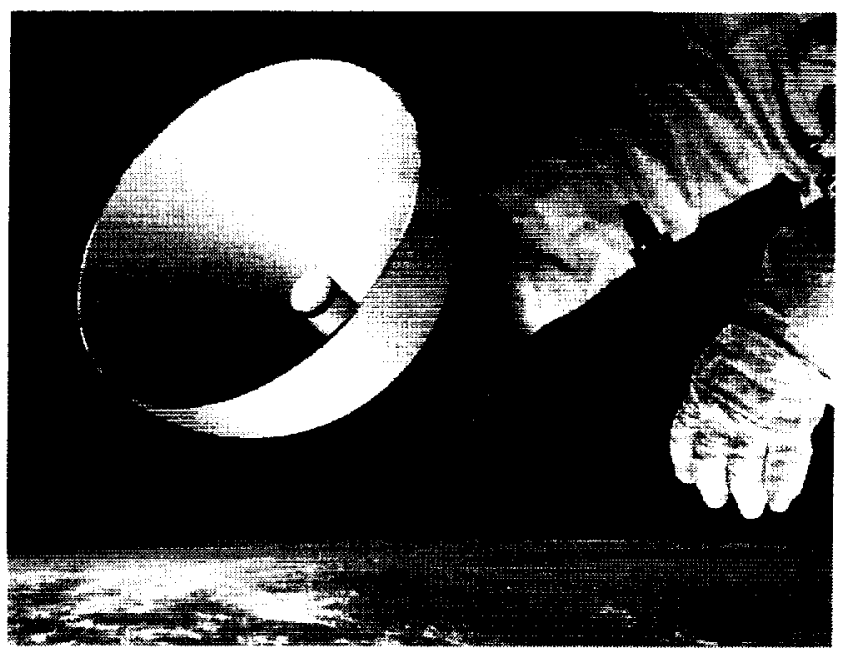

FIGURE 1. Artist's Concept for Solar Thermal Energy Conversion.

cylindrical target (Jaworske, 2001). Several of these coatings were evaluated for their durability in atomic oxygen and vacuum ultraviolet environments (Jaworske, 2002a). Coating thickness and chemical composition were also considered as variables in optical performance (Jaworske, 2002b).

This paper will focus on the high temperature durability of solar selective coatings composed of nickel and aluminum oxide, titanium and aluminum oxide, and platinum and aluminum oxide. To identify the durability of these coatings, the solar absorptance and infrared emittance of the candidate coatings were evaluated at room temperature, and then exposed to several ramp and soak profiles in the range of $400^{\circ} \mathrm{C}$ to $700^{\circ} \mathrm{C}$. Solar absorptance and infrared emittance were evaluated after high temperature exposure, and changes in optical performance are reported. Reflectance spectra are also presented, summarizing the transition from high solar absorptance to low infrared emittance.

\section{MATERIALS AND METHODS}

All coatings were deposited on nickel substrates, some on squares $1.0 \mathrm{~cm}$ on a side and others on disks $1.3 \mathrm{~cm}$ in diameter. Ion beam sputter deposition was used to deposit the coatings. For each coating type, a total of four nickel substrates and a fused silica witness coupon were utilized. Briefly, the ion beam was allowed to impinge on a cylindrical target composed of a varying amount metal and dielectric. The cylinder was rotated during deposition such that the composition of the coating varied through its thickness. The initial material to be deposited was primarily metal. The final material to be deposited was primarily dielectric. The cylinder was rotated in a step-wise fashion, such that the progression from metal to dielectric occurred in eleven discrete steps. The witness coupon adjacent to the nickel substrates was used to identify coating thickness.

The optical properties of solar absorptance, $\alpha$, and infrared emittance, $\varepsilon$, were evaluated utilizing a Perkin-Elmer Lambda-19 spectrophotometer equipped with a $15 \mathrm{~cm}$ diameter integrating sphere and a Surface Optics Corporation SOC-400t portable infrared reflectometer, respectively. Spectral reflectance obtained from the Lambda-19 was recorded in the wavelength range of 250 to 2500 nanometers, subtracted from unity, and weighted with respect to the air mass zero solar spectrum to yield $\alpha$. Spectral reflectance obtained from the SOC-400t was recorded in the wavelength range of 2 to 25 micrometers, subtracted from unity, and weighted with respect to the black body curve for $25^{\circ} \mathrm{C}$ to yield $\varepsilon$. In this mathematical treatment, $\alpha$ is temperature independent while $\varepsilon$ is temperature dependent. In addition, reflectance data from both techniques were plotted on a semi logarithmic scale to compare the sharp transition in optical properties before and after heating.

Heating was accomplished under flowing high purity nitrogen utilizing the furnace of a Perkin-Elmer DTA-1700 differential thermal analyzer. An individual sample was placed on top of two small graphite crucibles in the furnace. 
The thermocouples supplied by the manufacturer to measure temperature inside the furnace were adjacent to the bottom of the crucibles. The desired ramp and soak temperature profile was initiated using a programmable controller. The ramp rate for all samples was $20^{\circ} \mathrm{C} / \mathrm{min}$. The four soak temperatures selected for this work were: $460^{\circ} \mathrm{C}, 540^{\circ} \mathrm{C}, 610^{\circ} \mathrm{C}$, and $680^{\circ} \mathrm{C}$. Time at soak temperature for all samples was one hour. Cooling was accomplished by natural convection.

\section{RESULTS AND DISCUSSION}

The nickel/aluminum oxide cermet coatings were found to be $2200 \AA$ thick. Their average $\alpha$ before heating was 0.92 and their average $\varepsilon$ before heating was 0.20 . Figure 2 summarizes their high temperature durability before and after heating. At every temperature $\alpha$ decreased. The greatest decrease occurred at the highest temperature, decreasing to a value of 0.64 . At every temperature $\varepsilon$ also decreased. The decline in $\varepsilon$ was found to be similar at
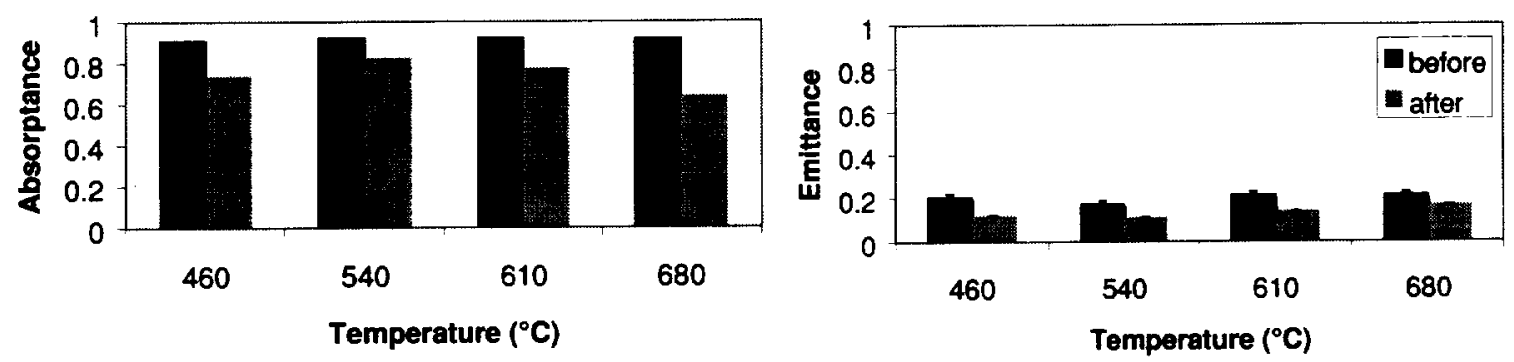

FIGURE 2. Solar Absorptance and Infrared Emittance Before and After Heating $\mathrm{Ni} / \mathrm{Al}_{2} \mathrm{O}_{3}$ Cermet Coatings.

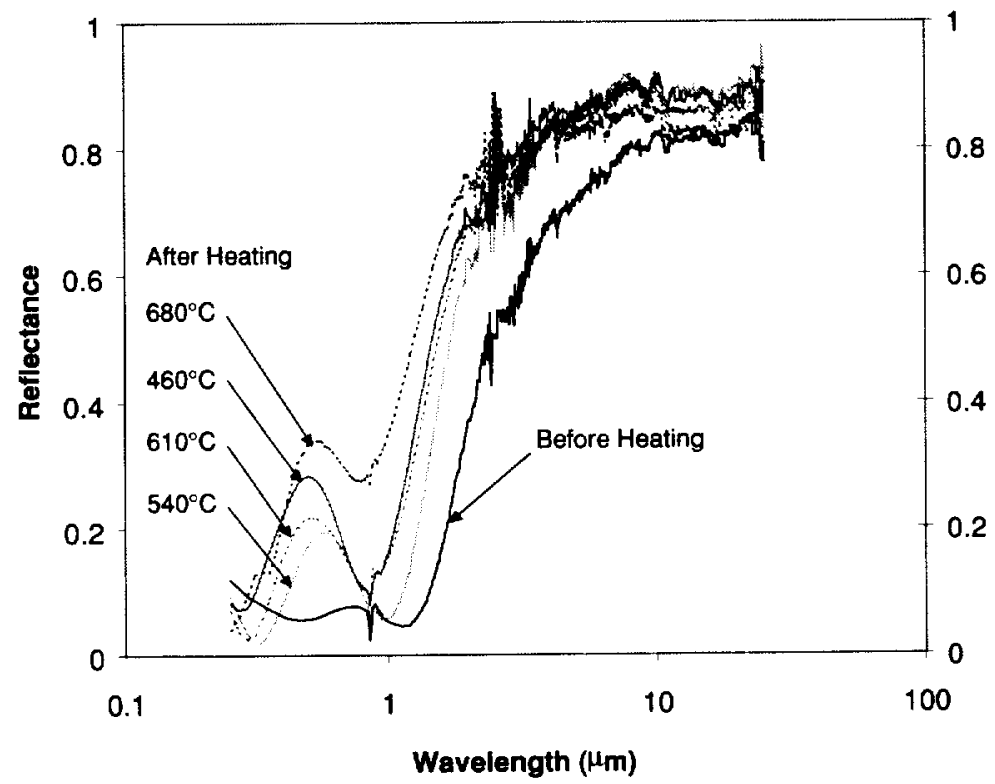

FIGURE 3. Reflectance of the $\mathrm{Ni} / \mathrm{Al}_{2} \mathrm{O}_{3}$ Cermet Coatings Before and After Heating.

all temperatures, suggesting an effect that was common to all samples, perhaps occurring early in the ramp and soak process. At the highest temperature, $\varepsilon$ decreased to a value of 0.17 . Figure 3 shows the change in reflectance. There is a shift to shorter wavelengths with increasing temperature and the reflectance in the visible increases slightly. Both the shift and the increase in reflectance contribute to the decrease in solar absorptance.

The titanium/aluminum oxide cermet coatings were found to be $2700 \AA$ thick. The average $\alpha$ before heating was 0.93 and the average $\varepsilon$ before heating was 0.09 . Figure 4 summarizes their high temperature durability before and 
after heating. In this case, $\alpha$ remained essentially constant after heating at every temperature, suggesting both repeatability and durability at elevated temperatures. At every temperature $\varepsilon$ also remained essentially constant. The average $\alpha$ after heating, 0.93 , and the average $\varepsilon$ after heating, 0.10 , confirm the lack of change in optical properties after heating. These observations are consistent with previous work on the oxides of titanium and aluminum (de Groh, 1994). The high $\alpha$ and low $\varepsilon$ values exhibited by the titanium/aluminum oxide cermet
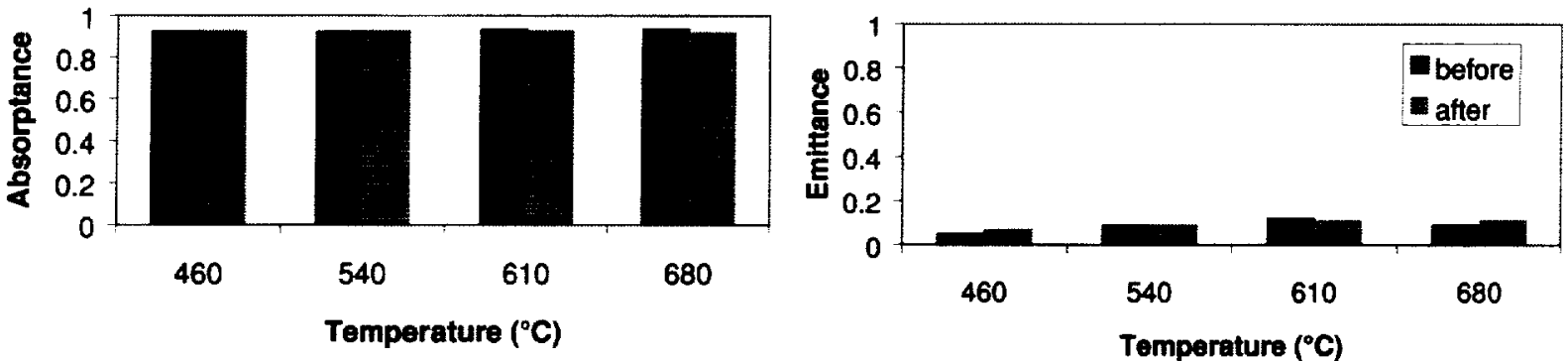

FIGURE 4. Solar Absorptance and Infrared Emittance Before and After Heating $\mathrm{Ti} / \mathrm{Al}_{2} \mathrm{O}_{3}$ Cermet Coatings.

coatings along with their durable nature at elevated temperatures suggest that this molecular mixture may be an attractive candidate for potential solar selective coating applications. The before and after reflectance values summarized in Figure 5 show little change in the visible or the infrared, consistent with the reported $\alpha$ and $\varepsilon$ values. In general, it is difficult to distinguish one curve from another. Some minor differences are observed in the transition zone created from merging the visible data from one instrument and the infrared data from another instrument.

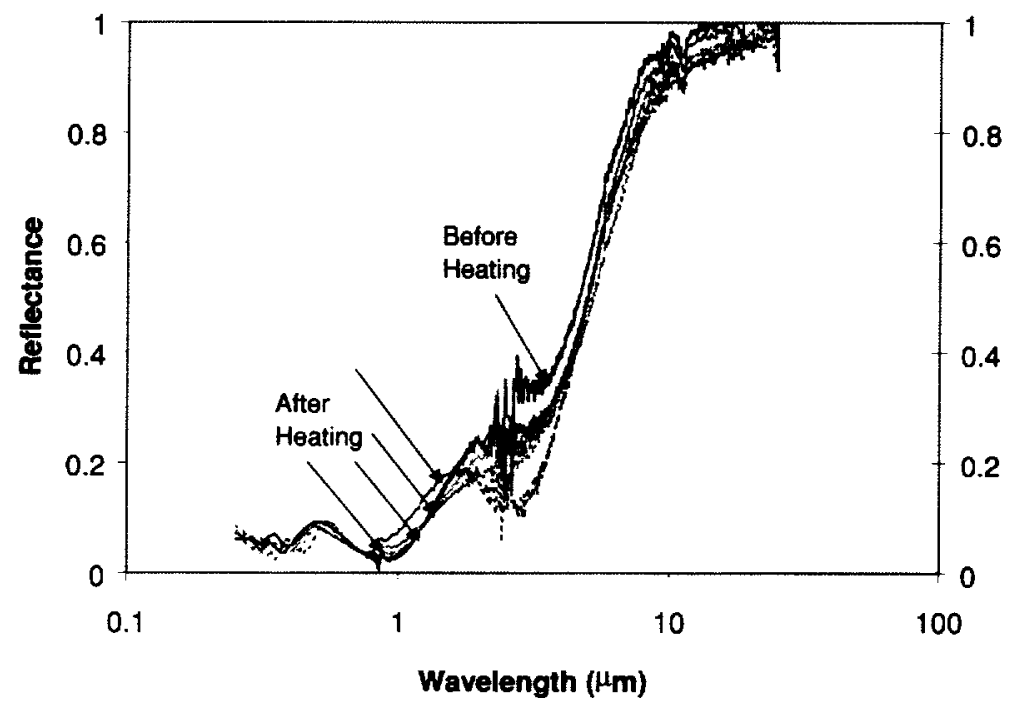

FIGURE 5. Reflectance of the $\mathrm{Ti} / \mathrm{Al}_{2} \mathrm{O}_{3}$ Cermet Coatings Before and After Heating.

The platinum/aluminum oxide cermet coatings were found to be $5000 \AA$ thick. Their average $\alpha$ before heating was 0.83 and their average $\varepsilon$ before heating was 0.08 . Figure 6 summarizes their high temperature durability before and after heating. In this case, $\alpha$ decreased at every temperature. Changes in $\varepsilon$ were minimal. At the highest temperature, $\alpha$ decreased to a value of 0.75 and $\varepsilon$ was essentially unchanged at a value of 0.08 . Figure 7 shows the change in reflectance before and after heating. The shift in reflectance at shorter wavelengths is consistent with the decrease in $\alpha$ and the similarity in reflectance at longer wavelengths is consistent with the minimal change in $\varepsilon$. 

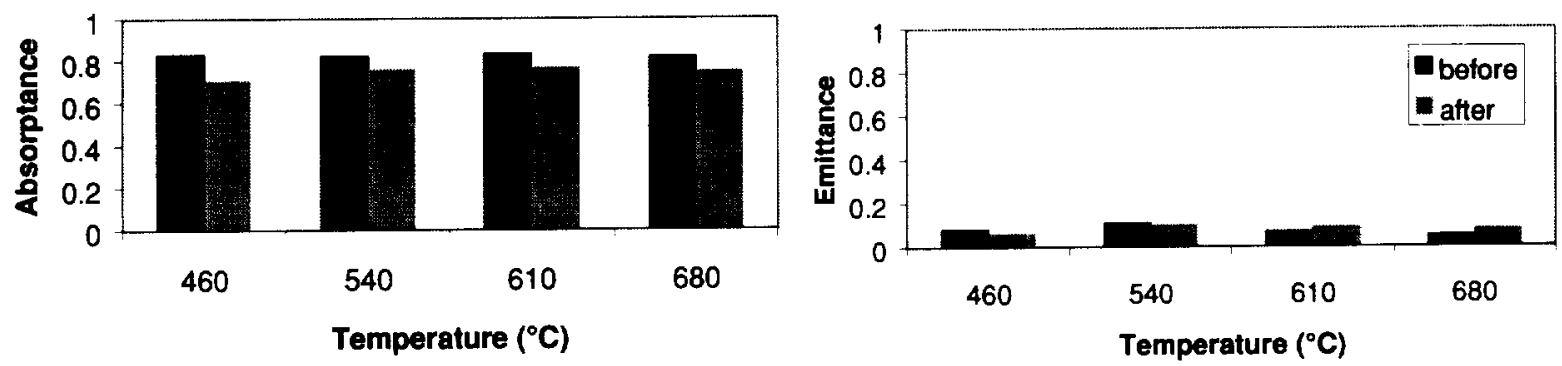

FIGURE 6. Solar Absorptance and Infrared Emittance Before and After Heating $\mathrm{P} U \mathrm{Al}_{2} \mathrm{O}_{3}$ Cermet Coatings.

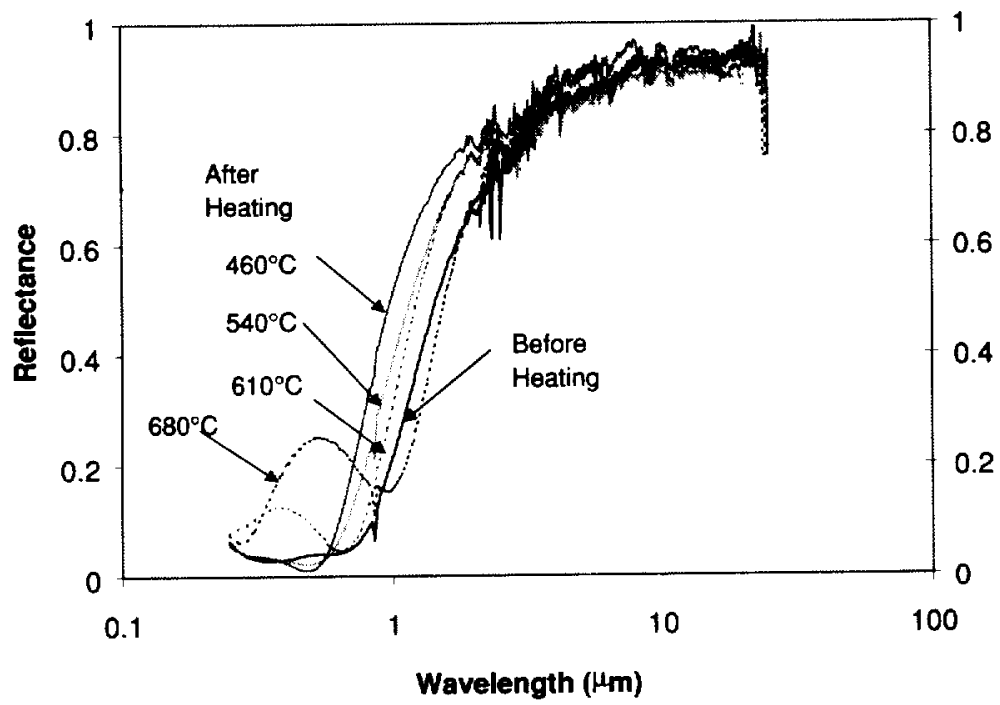

FIGURE 7. Reflectance of the $\mathrm{Pt} / \mathrm{Al}_{2} \mathrm{O}_{3}$ Cermet Coatings Before and After Heating.

\section{CONCLUSIONS}

The high temperature durability of several solar selective coatings was evaluated, and the most durable coating was found to be a molecular mixture of titanium and aluminum oxide. The $2700 \AA$ thick titanium and aluminum oxide cermet coating was manufactured using ion beam sputter deposition, and was purposely designed to be metal-rich near the substrate-coating interface and oxide-rich near the surface. The solar absorptance of this cermet coating on a nickel substrate was found to be 0.93 and the infrared emittance calculated at $25^{\circ} \mathrm{C}$ was found to be 0.09 . Exposure of this coating for one hour to temperatures of $460^{\circ} \mathrm{C}, 540^{\circ} \mathrm{C}, 610^{\circ} \mathrm{C}$, and $680^{\circ} \mathrm{C}$ under flowing nitrogen revealed essentially no change in spectral reflectance and no change in optical performance. Other molecular mixtures of nickel and aluminum oxide, and, platinum and aluminum oxide were found to be susceptible to the high temperature environment. These cermet coatings exhibited a decrease in solar absorptance after high temperature exposure, with little or no change in infrared emittance. High temperature durability is one prerequisite for utilizing solar selective coatings for heat engine and thermal bus applications in space power systems.

\section{REFERENCES}

de Groh, K. K., Roig, D. M., Burke, Christopher A., and Shah, Dilipkumer R., "Performance and Durability of High Emittance Heat Receiver Surfaces for Solar Dynamic Power Systems," NASA TM 106549, 1994.

Granqvist, C. G., Appl. Phys. A, 52, 83-93 (1991).

Hahn, R. E., and Seraphin, B. O., "Spectrally Selective Surfaces for Photothermal Solar Energy Conversion," in G. Hass and M. H. Francombe, eds, Physics of Thin Films, Volume 10, Academic Press, New York, 1978, pp. 1-69. 
Jaworske, D. A., and Hornacek, J., "Coatings for Solar Absorber Applications in Low Earth Orbit," 33 ${ }^{\text {rd }}$ International SAMPE Technical Conference, Seattle, WA, 2001, pp. 1573-1580.

Jaworske, D. A., "Durability of Solar Selective Coatings in a Simulated Space Environment," $34^{\text {th }}$ Intemational SAMPE Technical Conference, Baltimore, MD, 2002a.

Jaworske, D. A., and Shumway, D. A., "Optical Properties of Thin Film Molecular Mixtures," 5 th Conference on Aerospace Materials, Processes and Environmental Technology, Huntsville, AL, $2002 \mathrm{~b}$.

Zhang, Q., et al., J. Vac. Sci. Technol. A, 17(5), 2885-2890 (1999). 